\title{
Sartre e a psicanálise contemporânea
}

\author{
Camila Salles Gonçalves \\ Departamento de Psicanálise do Instituto Sedes Sapientiae
}

\begin{abstract}
resumo Este artigo mostra de que modo a tentativa de fundar uma psicanálise existencial permeia a obra filosófica de Sartre, faz referência a filosofias que são incorporadas e recriadas no processo de dar forma ao projeto de psicanálise existencial e analisa exemplos de como seria a psicanálise dele resultante. No final, sugere o modo pelo qual a análise crítica que Sartre realiza da psicanálise freudiana pode hoje inspirar o pensamento psicanalítico brasileiro contemporâneo.
\end{abstract}

palavras-chave psicanálise existencial; consciência; para-si; $e u$; transcendência; $e k$ stase; má-fé.

Vou fazer uma mínima travessia dos fundamentos que Sartre estabeleceu para seu projeto de psicanálise existencial, indicar o modo pelo qual este serve, também hoje, à revisão crítica da teoria freudiana e trazer exemplos de como sua filosofia é retomada por psicanalistas que examinam as bases da teoria psicanalítica.

Toda a obra filosófica de Sartre é atravessada por tentativas de encaminhar questões por meio da psicanálise. Primeiro, pela projeção de caricaturas da psicanálise freudiana sobre outras filosofias, na preparação do terreno para uma ontologia,já iniciada por recortes, ou apropriações parciais, da fenomenologia de Husserl. Depois, pelo desenvolvimento de uma crítica efetiva de teorias de Freud, que toma forma ao mesmo tempo que o projeto de fundar uma nova psicanálise, projeto este inseparável da ontologia fenomenológica que também absorve e reinterpreta idéias de Hegel e de Heidegger.

Recebido em 15 de maio de 2006. Aceito em 24 de julho de 2006.

doispontos, Curitiba, São Carlos, vol. 3, n. 2, p.53-67, outubro, 2006. 
Em um primeiro momento, em $A$ Transcendência do ego (1936), ao fazer uma crítica do modo de se referir ao eu adotado pela filosofia francesa, sobretudo aquela transmitida por seus mestres, Sart re a submete a uma redução à psicanálise, espécie peculiar de redução ao absurdo: atribui a adversários a convicção de que a consciência teria origem em algo que lhe seria anterior. Alguns filósofos estariam cometendo o mesmo erro que certos "psicólogos" ingênuos, ou freudianos, pois, mesmo admitindo que a consciência "não saía" do $e u$, teriam entendido que consciências espontâneas proviriam do inconsciente. Partindo do eu transcendental, eles teriam imaginado esse eu como um poder unificador emanando de "um inconsciente pré-empírico primordial" e reduzido o "eu penso kantiano" a uma instância psicológica. É ao longo dessa linha argumentativa, que encontramos a interpretação da famosa citação de Rimbaud, Je est un autre: "O contexto prova que ele [Rimbaud] simplesmente quis dizer que a espontaneidade das consciências não poderia emanar do eu, ela vai rumo ao Eu, ela o reúne, ela o deixa entrever sob sua espessura límpida, mas, antes de mais nada, mostra-se como espontaneidade individuada e impessoal"(Sartre, 1981, p.78-79). É dispensável a suposição de qualquer instância que tenha a função de referir a atividade da consciência a um sujeito, por mais abstrata e metafórica que seja. Por outro lado, qualquer teoria sobre a origem do pensar é aproximada de pressupostos psicanalíticos apresentados de forma caricatural: "A tese comumente aceita, segundo a qual nossos pensamentos jorrariam de um inconsciente impessoal e se 'personalizariam', tornando-se conscientes, parece-nos uma interp retação grosseira e materialista de uma intuição correta" (Sartre, 1981, p.79).

Recriando o ponto de partida de Husserl, Sartre quer tratar da abertura da consciência pessoal para o encanto e a terribilidade do mundo, sem recorrer ao pressuposto de algo que a precederia, como revela em seu famoso pequeno texto, que é quase um manifesto, "Uma idéia fundamental da Fenomenologia de Husserl: a intencionalidade": "Ser terrível é a propriedade de uma certa máscara japonesa; é uma propriedade inesgotável, irredutível, que constitui sua própria natureza e não a soma de nossas reações a um pedaço de madeira esculpida. Husserl reinstalou o horror e o encanto nas coisas" (Sartre, 1968, p.28). Apesar da retórica praticada também em $A$ transcendência do ego, não pretende que na Critica 
da Razão Pura exista a pressuposição de algo como uma pré-consciência. Mas, para defender seu ponto de partida, questiona até a concepção kantiana de eu transcendental, de uma representação pura que reúne um diverso, que, simplesmente, representa minhas representações como minhas. Apega-se a questões em relação eu transcendental tal como é concebido por Kant e, depois, tal como é retomado por Husserl, para justificar sua rejeição de grande parte da obra do próprio Husserl: “Após ter considerado que o Eu era uma produção sintética e transcendente da consciência (nas Investigações lógicas), ele voltou, em as Idéias, à tese clássica de um Eu transcendental que estaria como que entrincheirado atrás de cada consciência" (Sartre, 1981, p.20).

Sartre opta por desconhecer a relação do eu transcendental de Husserl com a epoché ou suspensão do juízo, parecendo não levar em conta afirmações do filósofo, como a seguinte: "pela epoché fenomenológica, reduzo o meu eu humano e natural e minha vida psíquica - domínio de minha experiência psicológica interna - a meu eu transcendental e fenomenológico, domínio da experiência interna transcendental e fenomenológica" (Husserl, 1986, p.22). Esta formulação importante, assim como muitas outras, é deixada de lado, para pôr em foco que a epoché permite que se conceba a consciência, mesmo a consciência transcendental, não mais como um conjunto de condições lógicas e de direito hipostasiadas, "não mais como um inconsciente flutuando entre o real e o ideal" (Sartre, 1981, p.19). Graças a façanhas como esta, que se vale de deslocamento de conceitos filosóficos, Sartre vai tramando a possibilidade de apresentação de um sujeito cuja complexidade poderia ser pensada e revelada por uma psicanálise que não se dissociaria da filosofia.

Recorrendo a recriações de conceitos e de métodos, mantém a concepção de consciência como intencionalidade, que, segundo uma fina observação de Lyotard, "permite efetuar a redução, sem perder o que é reduzido" (Lyotard, 1978, p.29). A redução fenomenológica de Husserl suspende o juízo sobre a coisa concreta, na medida em que conduz para uma mudança de registro, mas permanece o significado da percepção, o aspecto objetivo, "algo que pertence necessariamente à essência da percepção” (Husserl, 1962, parágrafo 89, p. 237-40). Sart re encontra condições de avançar, possibilitadas pelo fato de Husserl distinguir "diversos tipos de atos intencionais: imaginações, representações, 
experiências de outrem, intuições sensíveis e categoriais, atos de receptividade e da espontaneidade etc" (Lyotard, 1978, p.29). As descrições sartrianas, sem dúvida, apoiam-se nesta vertente da intencionalidade. Não cabe, nem é possível, verificar agora o que resta de fidelidade às filosofias de Husserl, de Heidegger e de Hegel, nas proposições, ou profissões de fé, que sustentam tais descrições. Do resíduo de questões sem encaminhamento, que é inoculado nos fundamentos da ontologia fenomenológica sartriana e influíram em seus destinos, tratei em outro lugar (Gonçalves, 1996). Agora, creio ser importante mencionar, nesta rápida incursão na cozinha da filosofia de Sartre, onde se misturam e transformam filosofias, um problema, que ele tem que enfrentar ao longo de sua obra filosófica, que é o da unidade ou não da consciência de si, que se imbrica com a crítica da psicanálise freudiana e está na fundação do projeto de psicanálise existencial.

A idéia de uma instância psíquica inconsciente é incompatível com a translucidez da consciência e as funções que esta desempenha não justificam a idéia de um eu interior. Sartre nos põe diante de uma consciência de si ao mesmo tempo racional, empírica e psicológica, e este é um dos modos pelos quais se apropria do pensamento de Husserl. Apoia-se na idéia de que a intencionalidade, enquanto abrir-se da consciência visando algo, já é, ao mesmo tempo, um movimento unificador. A consciência unifica-se ao transcender-se, ao lançar-se para fora de si, o que lhe permite afirmar: "a concepção fenomenológica da consciência torna o papel unificador e individualizador do Eu totalmente inútil. É a consciência, ao contrário, que torna possível a unidade e a personalidade de meu Eu, O Eu transcendental não tem pois razão de ser" (Sartre, 1981, p.23). Considera o eu psicofisico suficiente para o conhecimento objetivo e para referência das vivências num mundo em que se concebe de um novo modo a relação entre sujeito e objeto. Para além disso, "o eu não deve poder ser procurado nos estados de consciência irrefletidos nem atrás deles. O eu só aparece com o ato reflexivo" (Sartre, 1981, p.43), isto é, para uma consciência de segunda ordem.

Em O Ser e o Nada, são analisadas as estruturas do para-si, da realidade humana, a partir do princípio husserliano da consciência (toda consciência é consciência de) e da idéia de Heidegger de projeto ekstático. Ek-stase tem o sentido de "fora de si" (ausser sich) e projeto (Geworfenheit), de 
"modo de ser de um ente que é suas próprias possibilidades" (Heidegger, 1976, p.329, parágrafo 65). Em uma rara definição, Sart re escreve que o ek-stase é "a distância de si do para-si determinada pelo nada" (Sartre, 1960, p.183). A partir de leituras de Hegel, reinterp reta o nada como negação e desenvolve a análise descritiva da negação que determina essa distância. É deste modo que, na constituição da filosofia sartriana, Hegel sucede a Husserl: "A única ligação que Husserl pode estabelecer entre meu ser e o de outrem é a do conhecimento; ele não conseguiria pois, não mais que Kant, escapar ao solipsismo. Se, sem observarmos as regras da sucessão cronológica, nós nos conformarmos àquelas de uma dialética intemporal, a solução que Hegel dá ao problema, no primeiro volume da Fenomenologia do Espírito, parecer-nos-á realizar um progresso importante com relação àquela que Hegel propõe" (Sartre, 1960, p.291).

A realidade humana é descrita como consciência, também segundo o momento do reconhecimento, na Fenomenologia do Espírito de Hegel. O para-si é apresentado como "um ser que implica o ser de outrem em seu ser” (Sartre, 1960, p.301). A negação, tanto quanto a relação com outrem, constitui a marca de originalidade do primeiro projeto psicanalítico sartriano, esboçado no seu ensaio de ontologia fenomenológica, que constata: "o fato primeiro é a pluralidade de consciências e esta pluralidade é realizada sob a forma de uma dupla e recíproca relação de exclusão. Eis-nos em presença do vínculo (lien) de negação por interioridade" (Sartre, 1960, p. 291-292). A negação tem, por assim dizer, uma correspondência ontológica. É preciso levar-se sempre em conta que o para-si caracteriza-se por uma distância de si criada pela negação. A negação é "a estrutura de base da intencionalidade e da ipseidade" (Sartre, 1960, p.167). Este perfil da consciência ou para-si, que permite a Sart re dispensar um eu transcendental e as instâncias psíquicas da psicanálise de Freud, é também distância de si, relação de não ser: "a característica da ipseidade, com efeito, da Selbstheit, é que o homem é sempre separado do que ele é por toda a extensão do ser que ele não é” (Sartre, 1960, p.53).

Sartre desenvolve também a idéia segundo a qual a transcendência tem por origem a nadificação, que a caracteriza enquanto abrir-se para fora. A consciência nega de si o ser que ela não é. Há uma ligação de ser, que é a negação interna. Modifica a concepção heideggeriana de existência transcendente, ao longo de uma alentada discussão, em que diz que o filósofo "faz 


\section{8}

do Nada uma espécie de correlativo intencional da transcendência, sem ver que ele já o inseriu na própria transcendência, como sua estrutura original" (Sart re, 1960, p.55). Reafirma que na transcendência há uma "unidade ekstática", da qual faz parte uma "negação de interioridade". O para-si se faz para-si no modo não sendo. É presença ao ser, é intencionalmente dirigido para um outro ser ou para seu si.É presença ao ser através de uma ligação negativa de interioridade. Também a ipseidade é consciência (de) si do para-si que só se pode dar por meio da negação, também a "relação original com outrem" é uma "negação de interioridade" (Sartre, 1960, p.288), que põe a distinção original de outrem e de mim mesmo. A descrição fenomenológica do para-si é a descrição de seus ek-stases, isto é, seus modos de ser para fora de si, enquanto "ser que implica o ser de outrem em seu ser" (Sartre, 1960, p.301-302). A consciência de si vem a ser no perpétuo reenvio a um si, vivendo "o drama do ser que não pode ser objeto para si mesmo" (Sartre, 1960, p.298).

Além de constatarmos de que modo a questão da presença de um outro faz parte da existência, penso que, se quisermos ter uma concepção da subjetividade a partir de O Ser e o Nada, devemos levar em conta a questão dos sentidos do si do para-si, que é separado de si por um nada. Sartre escreveu: "é essa noção de si que é preciso estudar, pois ela define o ser da consciência” (Sartre, 1960, p.351). A fundação da psicanálise existencial jamais se completou e o fundador a ela se referia como algo que viria a ser. Os críticos de Sart re algumas vezes julgaram que essa psicanálise se esgotaria na análise que ele realiza da má-fé, entendida só como uma consciência que engana a si mesma. Mas uma leitura atenta de O Ser e o Nada evidencia que o projeto de psicanálise existencial, indissociável das análises ontológicas presentes nesta obra, não poderia se reduzir ao campo da má-fé e que este não poderia ser considerado isoladamente. Sobretudo, uma teoria psicanalítica sartriana teria que se construir a partir da concepção da relação do para-si consigo e com outrem. A má fé é um dos modos desta relação. Além das análises da má fé, outras descrições da ontologia fenomenológica sartriana, como as da contingência, da facticidade, do ser do valor, do ser dos possíveis, do eu, da temporalidade e da ipseidade, são indispensáveis para compreendermos projeto de psicanálise. E na concepção deste há uma asserção fundamental: o desejo prova a existência da falta (manque). Esta é, "de todas as negações internas, aquela 
que penetra mais profundamente no ser" (Sartre, 1960, p.148). O ser do homem, a existência, é caracterizada pela falta (manque) e pela presença de um outro, concebida por meio das leituras de Hegel: "Pela necessidade, em que eu sou, de não ser objeto para mim, senão lá no Outro, devo obter do outro o reconhecimento de meu ser" (Sartre, 1960, p.292). A incompletude do para-si encontra uma expressão que nunca mais a psicanálise, freudiana ou não, t eve condições de ignorar: "Que a realidade humana seja falta, a existência do desejo como fato humano seria suficiente para prová-lo" (Sartre, 1960, p.130).

Um dos pontos culminantes da análise descritiva da existência de outrem, em O Ser e o Nada, é o magistral capítulo IV, "Le Regard”, que fascinou Lacan, do qual cito este parágrafo, no qual Sart re afirmou, grafando Autre com maiúscula: "O Outro (L'Autre) só existe para a consciência como si-mesmo recusado. Mas, precisamente porque o Outro é um si mesmo, ele só pode ser, para mim e por mim, si-mesmo recusado, na medida em que ele é si-mesmo que me recusa. Eu não posso nem apreender nem conceber uma consciência que não me apreenda" (Sartre, 1960, p. 344-345). É conhecida a repercussão, mais ou menos vaga, do que está envolvido nesta dialética, nas inúmeras escolas de psicanálise lacaniana, que não pode ser agora esmiuçado e interpretado. Mas vale lembrar que esta dialética não pode ser dissociada do projeto de psicanálise, pois constitui o contexto em que ele se esboça.

Finalmente, vejamos como, mesmo sem a existência de uma clínica, Sartre se permite definir o objetivo do método da psicanálise existencial. Parte da relação da escolha, enquanto capacidade de decidir livremente, com a falta. O método deve visar "a significação fundamental" da escolha do analisando, o "segredo individual" (Sartre, 1960, p.651) de seu ser no mundo, seu projeto de ser. O projeto pode se reconhecido a partir da presença de um outro, de um psicanalista que deverá, a cada ocasião, "reinventar uma simbólica em função do caso que ele visa", sem submetê-lo a uma "simbólica universal" (Sartre, 1960, p.658). Não partiria de uma teoria, com uma decisão prévia a respeito de um ponto a que deveria chegar, mas encontraria o irredutível, deixando que este se anunciasse a si mesmo através de uma intuição evidente (Sartre, 1960, p.659-660). O método é revisto e re-situado bem mais tarde, na Crítica da Razão Dialética, mas tanto este esboço, quanto o segundo, estão na composição 
de O Idiota da Família. É preciso que voltemos a análises de O ser e o nada que fundamentam o primeiro.

Para o método reivindicar "como decisiva a intuição final do sujeito", é necessário retomar uma distinção: "a interpretação psicanalítica não faz tomar consciência do que ele é, ela o faz tomar conhecimento disso" (Sartre, 1960 , p.662). Notemos que a má fé não corresponde a uma mentira pura e simples, criada para substituir o inconsciente freudiano. Sobretudo, não está no lugar equivalente ao das instâncias psiquicas freudianas, mas é uma atitude escolhida para ser examinada, uma atitude existencial dentre outras, que permite descrever o modo pelo qual a consciência dirige a negação para si mesma: "Convém escolher e examinar uma atitude determinada que, ao mesmo tempo, seja essencial para a realidade humana e seja tal que a consciência, em vez de dirigir sua negação para o fora, faça-a voltar-se na direção de si própria. Essa atitude pareceu-nos dever ser a má-fé" (Sartre, 1960, p.85).

Sartre descobre inúmeros ardis da má fé que incidem sobre a duplicidade da realidade humana, enquanto ser para-si e ser-para-outrem. A má fé é um tipo de crença. É uma consciência (de) crença que afirma e nega a si mesma. Ao escrever que a anfibolia dos conceitos da má-fé "está fundada no ser do homem" (Sart re, 1960, p.109), Sartre parece brincar com o uso kantiano dessa palavra grega, que só tem aqui o sentido genérico de ambigüidade ou de palavra que significa duas ou mais coisas, e exibe uma série de jogos de que é capaz essa consciência (de) crença. Dou exemplo, tocando na famosa análise do olhar do outro: se sou fixada pelo olhar de um outro, a p reendida por uma consciência que sou impotente para desvendar e para alterar, posso simular: olho para um si congelado por um olhar de outro. Nego minha transcendência.Volto-me para minha consciência como se ela fosse a de um outro, fixada por mim.

Esboçando seu projeto de psicanálise existencial, Sartre realiza análises extremamente complexas das relações entre a consciência (de) má fé e os ek-stases do para-si. Desvenda as artimanhas por meio das quais aquela procura negá-los, ou jogar um contra o outro, ou fazer de conta que um é outro. O brilho, a complexidade e a engenhosidade destas análises incidem sobre uma consciência que jamais deixa de ser consciente, mas fabrica meios de não tomar conhecimento de si. Por exemplo, a má fé pretende me fazer coincidir comigo mesma, como um 
bloco de identidade, como uma coisa, como um em si, como se eu não fosse uma existência. Substitui, neste caso, a transcendência pela facticidade. Outro exemplo simplificado, j ogando com a temporalidade: nego meu passado, sou outra, nada mais carrego daquilo que fui. Ou, pior ainda, prometo ser sempre a mesma, negando a falta e o inevitável projetar-me no futuro, próprio da existência.

Na Crítica da Razão Dialética, Sartre refere-se a uma psicanálise que seria disciplina auxiliar do método dialético (Sartre, 1960, p.47) e, em O Idiota da Família, faz leituras da vida e da obra de Flaubert, utilizando ambos os projetos de psicanálise esboçados nas obras anteriores. Mostra, finalmente, seu método psicanalítico em ação, integrado pelo método progressivoregressivo, resgatado para acompanhar o movimento da História. Na biografia psicanálitico-existencial de Gustave Flaubert, além de situada segundo o método dialético heurístico, o desvendamento narrativo é possibilitado pela analítica do para-si. Detenhamo-nos em um parágrafo, que nos traz a situação em que Flaubert leva um tombo, sofre uma queda, em um momento decisivo de sua vida, momento de escolha. O escritor teria que voltar a Paris com o compromisso de voltar a estudar Direito, que ele detestava. Recusando-se, teria que permanecer com a família. Gustave cai, acometido por um ataque, semelhante a uma crise epilética:

"Se, finalmente ele cai como um pedaço de pau, é também para se livrar da intimidade e, portanto, da prisão forçada de interiorização. (...) Gustave permanecerá exterior a si mesmo, ele não terá mais si, far-se-á a encarnação provisória do ser-em-exterioridade; receberá de fora impulsos motores que se prolongarão em movimento, se nada de exterior vier a este se opor (...) Que calma mortuária: ele perde ao mesmo tempo a possibilidade de obedecer e o sonho de uma impossível revolta; o pedaço de pau não tem responsabilidade. À falta de ser um um pedaço de pau, o estado cadavérico servirá à sua intenção melhor do que a demência. Com efeito, não só porque representa o retorno do Para-si ao Em-si, mas também porque o tema de tornar-se coisa sempre acompanhou Gustave" (Sartre, 1960, p.216).

É claro que não precisamos acreditar na veracidade desta psicanálise, assim como não precisamos crer nas elucubrações de Freud para nos tornarmos psicanalistas. Em Uma recordação da infầncia de Leonardo da Vinci 
(1910), por exemplo, Freud desenvolve uma teoria a respeito da vida e das obras do artista e cunha o conceito de sublimação. São pensamentos psicanalíticos fora de sessões de psicanálise, desenvolvimentos metapsicológicos. Embora tenha sido contestada a leitura de fatos da vida de Leonardo em que se baseia, o sentido de conceitos-chave da psicanálise, tramados nesse texto, permanece. Em um texto de 1937, Freud abordou o papel da metapsicologia, ao imaginar, como fez tantas vezes, um interlocutor que a ele faria perguntas relativas a suas concepções teóricas, e respondeu citando Goethe: "So muss denn doch die Hexe dran', aqui a feiticeira precisa intervir. A saber, a feiticeira metapsicologia. Sem especulação e teorização metapsicológicas - quase diria: fantasia - não se dá aqui nenhum passo a mais" (Freud, apud Mezan, 2004, p. 101). Freud referiu-se deste modo a suas conjecturas metapsicológicas, assinalando a presença do encantamento da imaginação nas investigações e na criação de modos de descrever o funcionamento psíquico. Há um belíssimo artigo de Renato Mezan sobre o tema, "Metapsicologia/Fantasia", do qual recorto um comentário a respeito do modo pelo qual Freud introduz a metáfora da "domesticação (Bändigung) da pulsão". O autor faz-nos acompanhar, no texto freudiano, o momento em que este "abandona o tom altaneiro da exposição teórica para mergulhar num verdadeiro labirinto de imagens: caminhos da satisfação, caminhos pelos quais opera a terapia analítica". Observa, na sequência, que Freud admite que "por pouco" (beinahe) não disse "fantasiar", em vez de falar em "especulação" e "teorização". Faz o leitor acompanhar a "idéia furt iva (de Freud) de que "quase teria dito fantasia"" e mostra o ponto de grande interesse: "Ocorre aqui uma espécie de hesitação: a metapsicologia não é idêntica à fantasia, o que é marcado pelo 'quase' e pelo recurso gráfico dos travessões: mas tem com ela algum parentesco, já que a metapsicologia é uma feiticeira, personagem que, convenhamos, nada tem da racionalidade clara e distinta própria ao deus Logos" (Mezan, 2004, p.103-104).

É discutível o uso do nome metapsicologia para investigações teóricas como as de Sartre, que não partiu de uma experiência clínica, mas apenas da vivência de ser um homem entre os homens. Contudo, se lhe concedemos o direito de também criar uma metapsicologia feiticeira, esbocemos uma mínima interrogação a sua psicanálise: de que "intimidade subjetiva" e de que "prisão forçada de interiorização" estaria 
Gustave Flaubert querendo se livrar? A que vinha o esforço do escritor para não tomar conhecimento de si? A interiorização é um processo do sujeito, da ipseidade, do modo de estar con-si-go do para-si, que a consciência (de) má fé pode pretender anular. Já encontramos exemplos de como uma consciência pode se fazer consciência (de) crença na proximidade total consigo ou se assumir como uma essência que tem saber definitivo sobre si mesma, negando sua temporalidade, ou que, como olhar de um Outro, vê a si mesma. No caso de Gustave Flaubert, a descrição fenomenológica sartriana visa à singularidade da má-fé do analisando-personagem e sua virulência, a tentativa de aniquilar o próprio si, atitude radical na recusa em tomar conhecimento de si e na negação de seus possíveis. Gustave adoece, de um modo que vai além do se ver como em-si, que o faz adotar a aparência de em-si, como se tivesse se tornado coisa, pedaço de pau. Falo grosso modo, indico apenas a complexidade envolvida.

Hoje, nos minutos de que ainda disponho, quero pelo menos sugerir, dar idéia de modos pelos quais o percurso sartriano vem sendo integrado por certo pensamento psicanalítico brasileiro e nosso contemporâneo. Trata-se de pensamento que se pretende ainda freudiano, mas que faz a crítica da fundamentação teórica na sua origem, visando resgatar as condições de possibilidade de uso e de veracidade do método psicanalítico. Que ro citar outros dois pensadores brasileiros da psicanálise, grandes conhecedores da obra de Freud, Isaías Melsohn e Fabio Herrmann, que, afiados pela fenomenologia e pela filosofia de Sartre, dentre outras, realizam a crítica e elaboram suas próprias teorias, que têm como traço comum a condição de afastar riscos, tais como o de a psicanálise apegarse à uma concepção ingênua de um $e u$, à visão coisista do inconsciente, à visão positivista de realidade.

Em Psicanálise em nova chave, Isaías Melsohn acusa e revê o empirismo inglês pressuposto nas formulações de Freud, concepções do funcionamento das idéias-cópia, subjacentes a descrições do funcionamento do inconsciente. $\mathrm{Na}$ teoria freudiana, o processo primário tem como característica o livre escoamento da energia psíquica, que passa de uma representação para outra, segundo mecanismos de deslocamento e condensação, e o processo secundári o, a de a energia estar ligada antes de encontrar caminhos de escoamento. Essa hidráulica do psiquismo está formulada em conexão com a noção de representação: no processo primário há um 


\section{4}

investir em cheio, depositação plena de energia (libido) nas representações associadas com vivências de satisfação; no secundário, haveria modos mais estáveis de investimento, condições de controle do escoar da energia. Para Isaías Melsohn, Freud, como se poderia constatar em vários de seus escritos, "propõe que as impressões sensíveis devem servir a uma cópia fiel do mundo externo" e teria entendido que "todas as alterações dessa cópia seriam decorrentes da incidência do processo primário que alteraria a organização formal e a apreensão original - que seria a ve rdadeira - do significado dos objetos" (Melsohn, 2001, p.78). O conceito de representação inconsciente é pedra de toque da edificação teórica psicanalítica. Se a representação resulta de uma imaginação ou de uma percepção efetuada que funciona reapresentando ou deixando escapar imagens-coisa para a mente, o inconsciente funciona como um réservoir a estocar imagens-coisa que assomam na consciência do sujeito, dê-se ele conta disso ou não. Esta crítica, neste aspecto, não está muito longe da de Sartre, que denunciava "a linguagem e a mitologia coisista da psicanálise" (Sartre, 1960, p.91-92) e seu modelo de teoria mecânica, que permeia a referência a forças desencadeadas segundo o modelo de forças físicas. A fenomenologia inspira Isaías Melsohn em seus modos de conceber a consciência, o inconsciente, e a prática psicanalítica. $O$ autor aproxima a intenção, no sentido de Husserl, do conceito freudiano de impulso (Trieb), por exemplo, na releitura do chamado mecanismo de projeção."é errôneo dizer-se que estruturas objetais internas são projetadas nos objetos externos. O que se projeta é um movimento interior, é uma intenção, é o que Freud denominou impulso" (Melsohn, 2001, p.91). Estamos diante de uma obra que não pretende derrubar os fundamentos teóricos freudianos, mas reedificá-los, o que acaba resultando no favore-cimento da arte da interpretação. O objetivo desta, no exercício do método psicanalítico, é “a transformação da consciência do objeto em consciência de si" (Melsohn, 2001, p.275). O objeto não é algo depositado na consciência ou no inconsciente, pois estes nada contêm, mas "pontos momentaneamente estáveis por meio dos quais a estrutura de impulsos despertada pela experiência humana agora vivida", a experiência analítica, adquire"fixidez" (Melsohn, 2001, p.274) para o analisando. A intervenção do analista, resultando da invasão pela expressão da vivência emocional do paciente, consiste em comunicar a ele o sentido apreendi- 
do, formulado no cumprimento de uma dupla exigência, a de aceitar a invasão e acolhê-la. É assim que o analisando poderá "ouvir a si próprio falado por outrem; poderá se re-conhecer dentro e através do outro" (Melsohn, 2001, p.276).

A extensa obra de Fabio Herrmann teve sua publicação iniciada pelos três volumes que compõem Andaimes do real, que inauguram um exame profundo e sistemático da teoria e do método da psicanálise. O autor retoma o pensamento freudiano, admitindo, não um inconsciente substancial, mas que "há o inconsciente". Para ele, um dos principais equívocos da psicanálise reside na idéia de consciência inconsciente, geradora de outras, contraditórias em termos tais como percepção inconsciente, memória inconsciente, sentir inconsciente. É claro, para seus leitores, que ele não faz meras transposições diretas de idéias de Sartre e Merleau-Ponty, mas Fabio Herrmann jamais procurou esconder o interesse com o qual leu A Fenomenologia da percepção e O Ser e o Nada. No segundo volume da trilogia dos Andaimes, cujo título é Psicanálise do quotidiano, estabelece a diferença entre real e realidade, fundamental para o esclarecimento da teoria psicanalítica. A realidade é o modo pelo qual representamos o mundo enquanto aparência do real, "representação aparencial do mundo". O real é um processo de produção de realidade e de identidade, que não aparece, que inclui a psique, que é um de seus estratos, e é deste que se ocupa a psicanálise. No livro $A$ Psique e o Eu, Fabio Herrmann diagnostica: "As dificuldades que encontraremos ao repensar a posição do eu na teoria psicanalítica derivam, na sua maior parte, da ambigüidade que habita o miolo mesmo da Psicanálise e que vimos representada pelas teorias explícita e implícita que leituras diferentes de Freud permitem destacar" (Herrmann, 1999, p.27). O autor realiza, a partir da leitura crítica de Freud, o redimensionamento das noções de eu e de realidade. Para ele, a noção de $e u$ está ligada a um modelo do psiquismo, do sujeito e da realidade que, por ser intuitivo e usual, geralmente nos escapa quando estudamos Psicanálise: "não acreditamos estar diante de um modelo, mas da verdade pura e simples" (Herrmann, 1999, p.29). Inspira-se em Sartre, em suas análises dos esforços desempenhados pelo sujeito para negar a contingência, para coincidir consigo mesmo, e sobretudo, quando trabalha na sua própria teoria da crença, diretamente relacionada com a clínica psicanalítica. Mostra várias situações em que a interpretação do analista é 
chamada a um duelo com a crença que sustenta as representações e autore presentações do analisando. Dá-se um jogo, no qual, a crença, tensionada pelo risco de desre presentação de sua vida psíquica, reage, põe-se em estado de alerta, torna-se hiper-dimensionada.

Não posso avançar neste assunto agora e é claro que meras aproximações entre teorias e textos, de autores que investigam e descrevem a psique, de nada serviriam se pretendêssemos eleger a teoria de fundamentação mais consistente ou verossímil. Mas vale indicar a preocupação de Sartre e dos autores citados em recuperar a psicanálise enquanto método heurístico e, ainda, vale lembrar que, se com a Crítica da Razão Dialética, Sartre pretendia desmecanizar a filosofia da história, hoje, seu pensamento crítico instiga o trabalho crítico que visa desmecanizar a teoria e a clínica psicanalíticas.

\section{Referências Bibliográficas}

HEIDEGGER, M. 1976. Sein und Zeit. Tübingen: Max Niemeyer.

HERRMANN, F. 1999. A Psique e o Eu. São Paulo: Hepyché.

HUSSERL, E. 1986. A Idéia de Fenomenologia. Lisboa, Edições 70. 1962. Ideas - General Introduction to Pure Phenomenology.

New York: Collier Books.

LYOTARD, J.-F. 1978. La Phénoménologie. Paris: P.U.F.

MELSOHN, I. 2001. Psicanálise em Nova Chave. São Paulo: Perspectiva.

MEZAN, R. 2004. “Metapsicologia/Fantasia”, Jornal de Psicanálise, Instituto de Psicanálise "Durval Marcondes". Sociedade Brasileira de Psicanálise de São Paulo. São Paulo.Volume 37 - número 68, 97-121. SALLES GONÇALVES, C. 1996. Desilusão e História na Psicanálise de J.-P. Sartre. São Paulo: Nova Alexandria.

SARTRE, J.-P. 1960. L'Être et le Néant. Paris: Gallimard. 1968. Situações I. Lisboa: Europa América. 
1971. L'Idiot de la Famille. Paris: Gallimard.

1981. La Transcendance de l'ego. Paris:Vrin.

1960. Critique de la Raison Dialectique. Paris: Gallimard.

doispontos, Curitiba, São Carlos, vol. 3, n. 2, p.53-67, outubro, 2006. 
○

O 